\title{
Post-Irradiation Analysis of Additively Manufactured Stainless Steel 316L Specimens
}

Jeffrey king ${ }^{1}$, Ryan Collette ${ }^{2}$, Behnam Amin-Ahmadi ${ }^{2}$, Sheng Cheng ${ }^{3}$ and Yaqiao $\mathrm{Wu}^{3}$

${ }^{1}$ Colorado School of Mines, Golden, Colorado, United States, ${ }^{2}$ Colorado School of Mines, United States, ${ }^{3}$ Center for Advanced Energy Studies/Microscopy and Characterization Suite, United States

The nuclear industry is exploring additive manufacturing technologies for reactor internal applications in order to enhance performance, reduce economic costs, and shorten production cycles (Bergeron and Crigger, 2018; Song et al., 2019). Nuclear reactor materials are known to be susceptible to hardening and embrittlement, irradiation-assisted stress corrosion cracking, and void swelling when exposed to high temperature radiation fields for long periods of time (Was and Andresen, 2012). Austenitic stainless steels are a leading candidate to demonstrate AM in nuclear applications given their weldability, good mechanical properties, and corrosion resistance at high temperatures (Şahin and Übeyli, 2008). Stainless steel 316L (SS-316L) has the added benefit of an extensive history of use in a variety of reactor applications as well as a wide availability of alloy powders in the particle size specifications necessary for compatibility with the laser-based additive manufacturing processes.

In laser-based additive manufacturing methods, the extreme processing conditions result in solidification rates and thermal stresses that are orders of magnitude larger than those observed in conventionally manufactured materials such as cast or welded metals (Frazier, 2014). These processing conditions offer the opportunity to design new microstructures that translate to material properties equivalent to, or in some cases, superior to conventionally made materials. Additively manufactured SS-316L (AM SS-316L) is one such example of this benefit, as numerous studies have shown that the resulting material exhibits a combination of high yield strength and tensile ductility (properties that are traditionally considered to be trade-offs) surpassing that of conventionally made SS-316L (Liu et al., 2017; Wang et al., 2018; Shang et al., 2019). This benefit is attributed to a sub-grain cellular dislocation network that impedes dislocation motion, increases dislocation storage and yield strength, and simultaneously enables impeded dislocations to slip through the dislocation cell walls at high stresses through nano-twin formation, resulting in stable plastic flow and enhanced ductility (Liu et al., 2018).

This work is part of a larger study at the Colorado School of Mines in collaboration with the Nuclear Science User Facilities and the Advanced Test Reactor (ATR) at the Idaho National Laboratory to assess the irradiation performance of metallic components produced by commercially available additive manufacturing techniques. The ATR irradiated alloy specimens to doses of $\sim 0.5$ and $\sim 1.5$ dpa at 256-281 ${ }^{\circ} \mathrm{C}$ to study the influence of the cellular dislocation structures on radiation tolerance. The cellular dislocation structures experienced dramatic change in all irradiated specimens. The cell boundaries were still identifiable after neutron irradiation to $\sim 0.5 \mathrm{dpa}$; but, the dislocation density in each specimen was significantly reduced and the cell walls were visibly dispersed. The irradiated microstructures in both the laser powder bed fusion (Figure 1) and laser powder feed (Figure 2) samples were dominated by defect clusters ('black dots', or small Frank loops). At $\sim 1.5$ dpa, the 'black dot' defect cluster size and density increased despite historical evidence that suggests faulted loops should be more abundant under these conditions. This observation, coupled with evidence of denuded zones adjacent to the dislocation cell boundaries suggests that the solidification-induced dislocation cell boundaries function as efficient sinks for point defects. The cellular structures in AM SS-316L appear to increase the dose necessary to reach a steady state defect cluster population. 


\section{Acknowledgements}

The project is financially supported by the US Department of Energy and the Nuclear Science User Facilities under grant DE-NE0008590. The support of the Center for Advanced Energy StudiesMicroscopy and Characterization Suite (CAES-MaCS) is gratefully acknowledged. Several individuals from the Idaho National Laboratory also supported the project; Katie Anderson and Craig Tyler's coordination of the irradiation experiment is appreciated, as is Donna Guillen, Collin Knight, and Jeremy Burgener's coordination of the post irradiation examination.
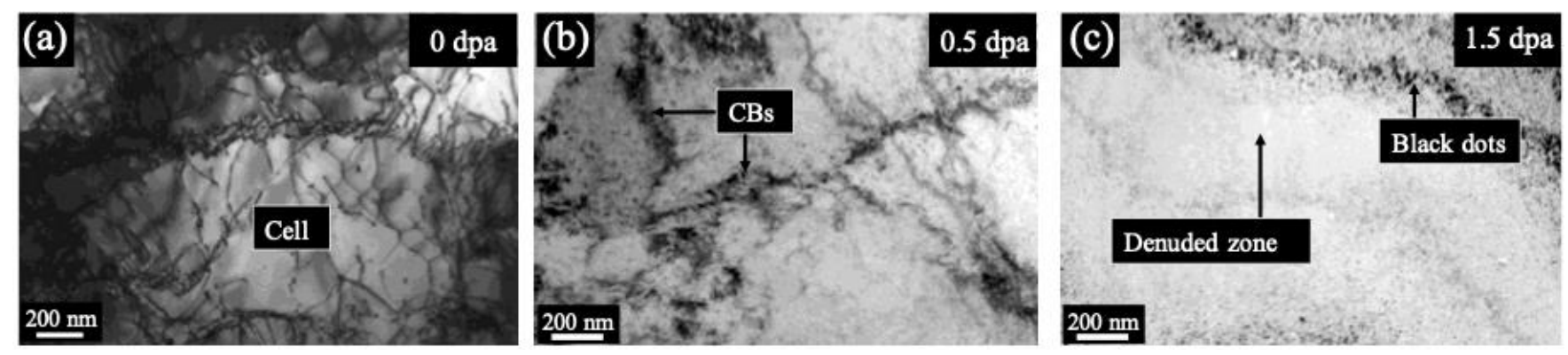

Figure 1. Comparison of cellular dislocation structure morphology (a) after heat treatment and (b-c) after neutron irradiation in AM SS-316L produced by laser powder bed fusion.
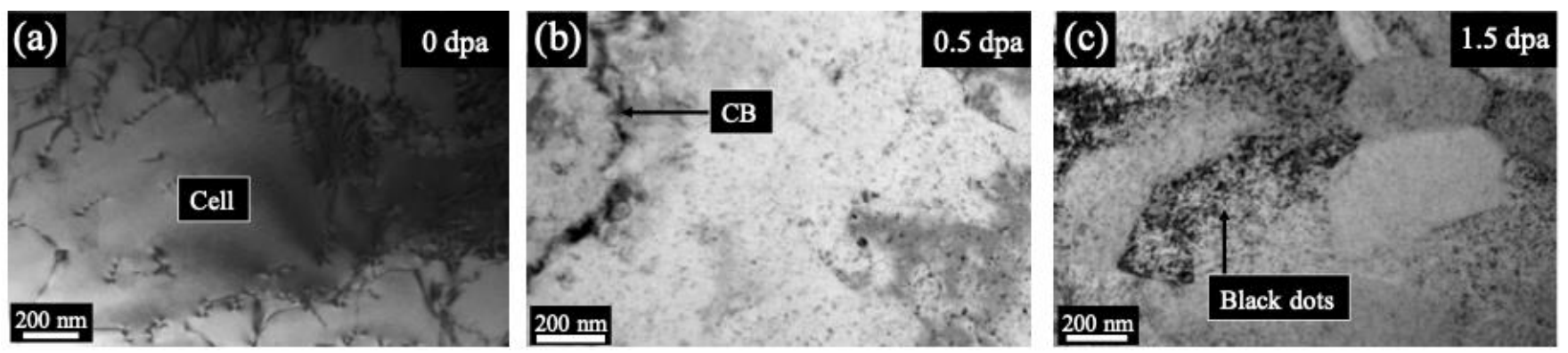

Figure 2. Comparison of cellular dislocation structure morphology (a) after heat treatment and (b-c) after neutron irradiation in AM SS-316L produced by laser powder feed.

\section{References}

Bergeron, A., and Crigger, J. B., "Early progress on additive manufacturing of nuclear fuel materials," Journal of Nuclear Materials, 2018, vol. 508, pp. 344-347, doi: 10.1016/j.jnucmat.2018.05.058.

Frazier, W.E., "Metal Additive Manufacturing: A Review," Journal of Materials Engineering and Performance, 2014, vol. 23, 1917-1928, doi: 10.1007/s11665-014-0958-z.

Liu, L., Ding, Q., Zhong, Y., Zou, J., Wu, J., Chiu, Y. L., Li, J., Zhang, Z., Yu, Q. and Shen, Z., "Dislocation network in additive manufactured steel breaks strength-ductility trade-off," Materials Today, 2018, vol. 21, pp. 354-361, doi: 10.1016/j.mattod.2017.11.004.

Şahin, S., and Übeyli, M., "A Review on the Potential Use of Austenitic Stainless Steels in Nuclear Fusion Reactors," Journal of Fusion Energy, 2008, vol. 27, pp. 271-277, doi: 10.1007/s10894-008-9136-3.

Shang, Z., Fan, C., Xue, S., Ding, J., Li, J., Voisin, T., Wang, Y. M., Wang, H. and Zhang, X., " Response of solidification cellular structures in additively manufactured 316 stainless steel to heavy ion irradiation: 
an in situ study ," Materials Research Letters, 2019, vol. 7, pp. 290-297, doi: 10.1080/21663831.2019.1604442.

Song, M., Wang, M., Lou, X., Rebak, R. B. and Was, G. S., "Radiation damage and irradiation-assisted stress corrosion cracking of additively manufactured 316L stainless steels," Journal of Nuclear Materials, 2019, vol. 513, pp. 33-44, doi: 10.1016/j.jnucmat.2018.10.044.

Wang, Y. M., Voisin, T., McKeown, J. T., Ye, J., Calta, N. P., Li, Z., Zeng, Z., Zhang, Y., Chen, W., Roehling, T. T., Ott, R. T., Santala, M. K., Depond, P. J., Matthews, M. J., Hamza, A. V. and Zhu, T., "Additively manufactured hierarchical stainless steels with high strength and ductility," Nature Materials, 2018, vol. 17, pp 63-71, doi: 10.1038/NMAT5021.

Was, G. S., and Andresen, P. L., Nuclear Corrosion Science and Engineering, A volume in Woodhead Publishing Series in Energy, 2012, ISBN: 978-1-84569-765-5. 